\title{
SEISMIC ASSESSMENT OF A MONUMENTAL MASONRY CONSTRUCTION: THE ROCCA ALBORNOZIANA OF SPOLETO
}

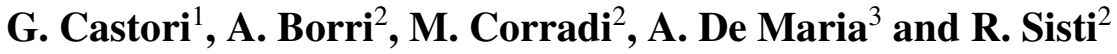 \\ ${ }^{1}$ Department of Engineering, University of Perugia \\ via Duranti 93, 06125 Perugia, Italy \\ e-mail: giulio.castori@unipg.it \\ ${ }^{2}$ Department of Engineering, University of Perugia \\ via Duranti 93, 06125 Perugia, Italy \\ antonio.borri@unipg.it, marco.corradi@unipg.it, romina.sisti@unipg.it \\ ${ }^{3}$ Ufficio Vigilanza e Controllo sulle Costruzioni, Region of Umbria \\ Via Palermo 106, 06129 Perugia, Italy \\ ale.dm2002@libero.it
}

Keywords: Military constructions, historic masonry, numerical analysis.

\begin{abstract}
The structural analysis of monumental constructions requires considering safety and conservation objectives, including the possible presence of artistic assets. In order to face these issues, this paper presents the results of a diagnostic analysis carried out on a 14th-century fortress: the Rocca Albornoziana of Spoleto in Umbria. Within this context, particular attention was de-voted to the choice of the most reliable modelling strategy for the application of the displacement approach in the seismic Performance-Based Assessment (PBA) procedure, as a function of different possible seismic behaviors. Seismic vulnerability was evaluated using a pushover method, and the results obtained with the nonlinear numerical model have been compared with the simplified schemes of the limit analysis. The capacity of the fortress to withstand lateral loads was evaluated with the expected demands resulting from the seismic action. By comparing the seismic demand with capacity, the high vulnerability to extensive damage and collapse, as frequently observed in similar buildings, was demonstrated. The aim of this study was to take into account both the qualitative, related to the technology of construction and to the rule-of-the-art, and the quantitative aspects of the numerical analysis of the structural loadbearing elements.
\end{abstract}




\section{INTRODUCTION}

A growing attention in the conservation of historic masonry constructions has created a need for new methods for the classification and analysis of ancient masonry structures and single structural elements, such wall panels, vaults, columns and buttresses and non-structural assets, such frescos, decorations, statues, etc. Because historic constructions may give a significant contribution to knowledge and understanding of the past, substantial harm to, or loss of, the significance of a listed structure should be always avoided when works are proposed for development-, conservation- or presentation-related purposes. Upgrading and restorations works should have a minimal impact on the cultural significance of the construction and meet the requirements of the "Minimum Intervention". Minimum intervention can be defined as a philosophy of designing repair and reinforcement works with the characteristics to be minimally invasive, cultural significance-friendly and reversible.

Conservation bodies do not easily grant permission for destructive or partially destructive testing campaigns and structural engineers can only rely on non-destructive testing to study the behavior of listed constructions (visual analyses, video-endoscopy of cavities, termo-photography, chemical analysis of mortars, etc.).

However, it is recognized that little increase in knowledge and understanding can be achieved using non-destructive techniques without conducting a numerical simulation. In this context, a comprehensive validation and calibration are a necessity for any numerical simulation method. Over the last two decades, researchers have dedicated a great deal of effort to verify the accuracy of non-linear numerical investigations of masonry structures. Validation is particularly important for historic masonry constructions, especially in earthquake prone areas since these numerical analyses are often used in many restoration and reinforcement projects, which have life-safety considerations.

The use of rubble stonemasonry wall panels in historic constructions along the ApennineBalkan seismic belt from Central Europe to the Middle East has been attributed to ease of availability and low cost. However, this common masonry typology has been used for centuries not only for standard rural residences, but also for important constructions (civic, military and religious structures) and it has demonstrated to have a very weak performance under an extreme seismic event.

The primary goal of a numerical simulation is to identify critical structural situations, estimate safety. Traditional quantitative and qualitative simulations are both able to predict the structural behavior of an element or of the whole masonry construction. However, qualitative studies are often preferred in order to acquire information on the structural behavior of historic constructions. Numerous papers have been recently published that contain qualitative analyses and it was concluded that valuable insight may be gained via a qualitative approach, due to the uncertainties and constraints common for historic masonry constructions.

In order to face these issues, research was carried out by the University of Perugia starting from a convention with the General Directorate for the Landscape, Fine Arts, Architecture, and Contemporary Art (DG PaBAAC) within the Ministry of Cultural Heritage and Activities and Tourism (MiBACT) regarding verification of the seismic safety of national museums in earthquake-prone areas such as the Umbria Region. More specifically, this paper presents the results of a non-linear numerical investigation carried out on a $14^{\text {th }}$-century fortress: the Rocca Albornoziana of Spoleto in Umbria, which currently houses a national museum. Different modelling strategies have been used with the aim at identifying the most reliable. The construction's vulnerability against seismic action was evaluated using the pushover method, and the results obtained with the nonlinear numerical model have been compared with the simplified schemes of 
the limit analysis. The capacity of the fortress to withstand lateral loads was evaluated with the expected demands resulting from the seismic action.

\section{STRUCTURAL ANALYSIS METHODOLOGY}

The structural damage assessment after an earthquake provides important information for the understanding of the construction response to the seismic event. More specifically, such an evaluation, based on criteria and methods that can guarantee an objective evaluation of the damage, is aimed to find the best correlation between structural damage and the related mechanisms.

Direct observation of crack patterns recorded in post-earthquake damage surveys [2], together with the available literature on reconnaissance of the damage suffered by existing masonry buildings [3][4], yielded to the conclusion that the seismic vulnerability of masonry structures depends on three different types of failure mechanisms:

- Masonry damage mechanisms = the response of existing masonry buildings can be governed by such mechanisms when, due to the poor quality of building materials and their construction type, masonry is not able to resist and transfer the vertical and seismic forces without breaking up (lack of monolithic behavior);

- Local damage mechanisms = the response of existing masonry buildings can be governed by local failure modes (out-of-plane response) when the good quality of the masonry is able to ensure a monolithic behavior, but the inadequate or nonexistent connections among structural elements (e.g. due to the lack of ring beams, tie rods or interlocking at the connection of intersecting walls) as well as the lack of any diaphragm action of horizontal bearing elements (due to the presence of in-plane flexible diaphragms such as thrusting roofs or simply supported timber floors) limit the capability to redistribute the seismic loads between the structural elements;

- Global damage mechanisms = the response of existing masonry buildings can be governed by global failure modes (in-plane response) only if the good quality of the masonry is able to ensure a monolithic behavior and the effective strong connection among structural components as well as the presence of rigid horizontal diaphragms allow to stabilize and promote the box-like behavior of the construction.

Within this context, the central objective of the present research was to contribute, through the application of a step-by-step analysis procedure on the Rocca Albornoziana fortress (Figure 1 ), to the calibration and validation of a general methodology for the assessment of the seismic vulnerability of heritage structures.

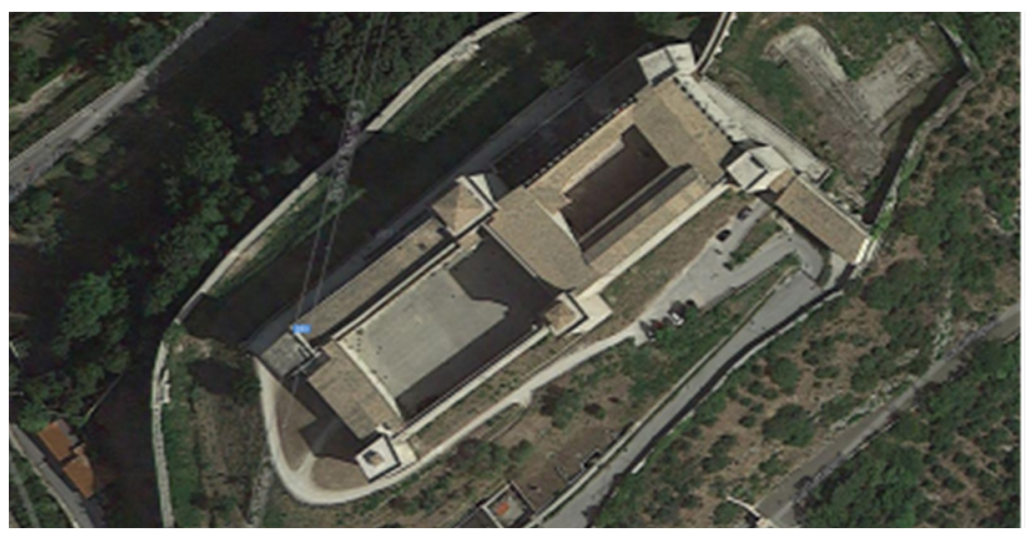

Figure 1: Rocca Albornoziana fortress: the external shape. 
To this end, the paper is aimed to propose a performance based multi-scale approach based on the use of three modelling strategies of different complexity (Table 1): Masonry Quality Index (MQI) method, Rigid Macro-block (RMB) method and Equivalent Frame (EF) method.

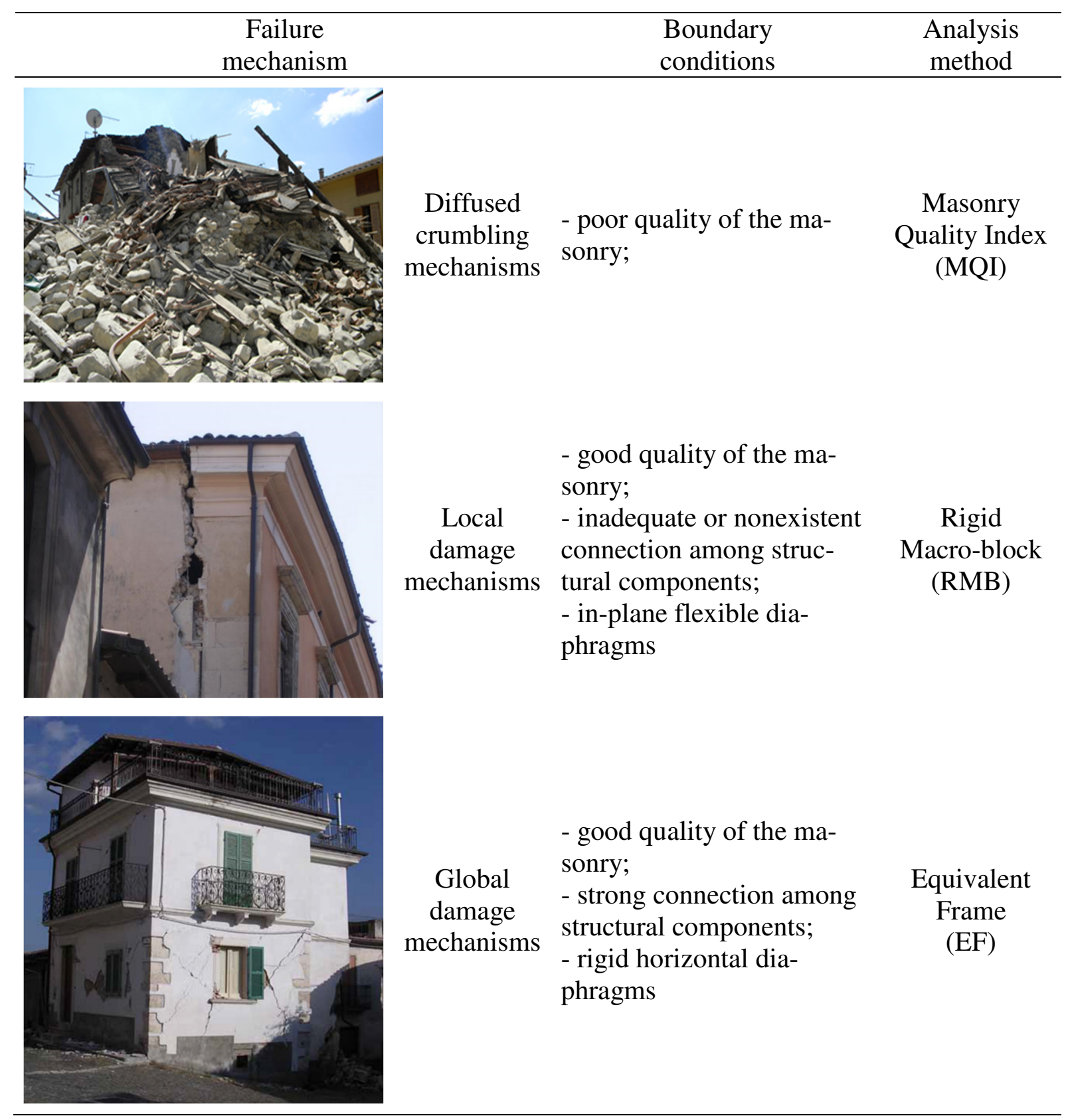

Table 1: Evaluation procedure used for the analysis of the seismic vulnerability.

At meso-scale level, a quick evaluation procedure, based on the determination of a Masonry Quality Index (MQI) [5], was used to express a synthetic judgment about the masonry quality (evaluated with respect to the "rules of art") and the related vulnerability against seismic actions.

At macro-scale level, a macro-element approach based on the limit analysis theorems (Rigid Macro-Block method, RMB) was performed on some elementary macro-elements that, being not able to redistribute their seismic forces to the rest of the building, can be assumed as rigid and cannot be accurately analyze by a global model. Since, at this scale level, comprehensive 
assessment would also require to analyze possible global collapse mechanisms, a three-dimensional (3D) pushover analysis (Equivalent Frame method, EF) was used complementarily to the local analysis to investigate the global structural performance of the building.

\subsection{Masonry Quality Index (MQI) method}

Since - according to the guidelines developed by the Umbrian design codes [6] and the ReLUIS research project [7] - the construction type, quality and state of preservation of masonry play a fundamental role in determining the capacity of a construction to sustain seismic actions, a relationship may be found between the variation of the damaging pattern (from large mechanisms to diffused crumbling) and masonry quality.

Under such conditions, the results of a non-destructive visual method (Masonry Quality Index method, described in detail in [5]) were used in order to provide a numerical estimate of the seismic vulnerability of the masonry walls.

To this end, starting from a material survey aimed to investigate the morphology and the composition of the masonry of the bearing walls, it was possible to detect the presence of two different masonry texture types (Figure 2): a) uncut stone masonry with facing walls of limited thickness and infill core (US type); b) dressed rectangular (ashlar) stone masonry (RS type).

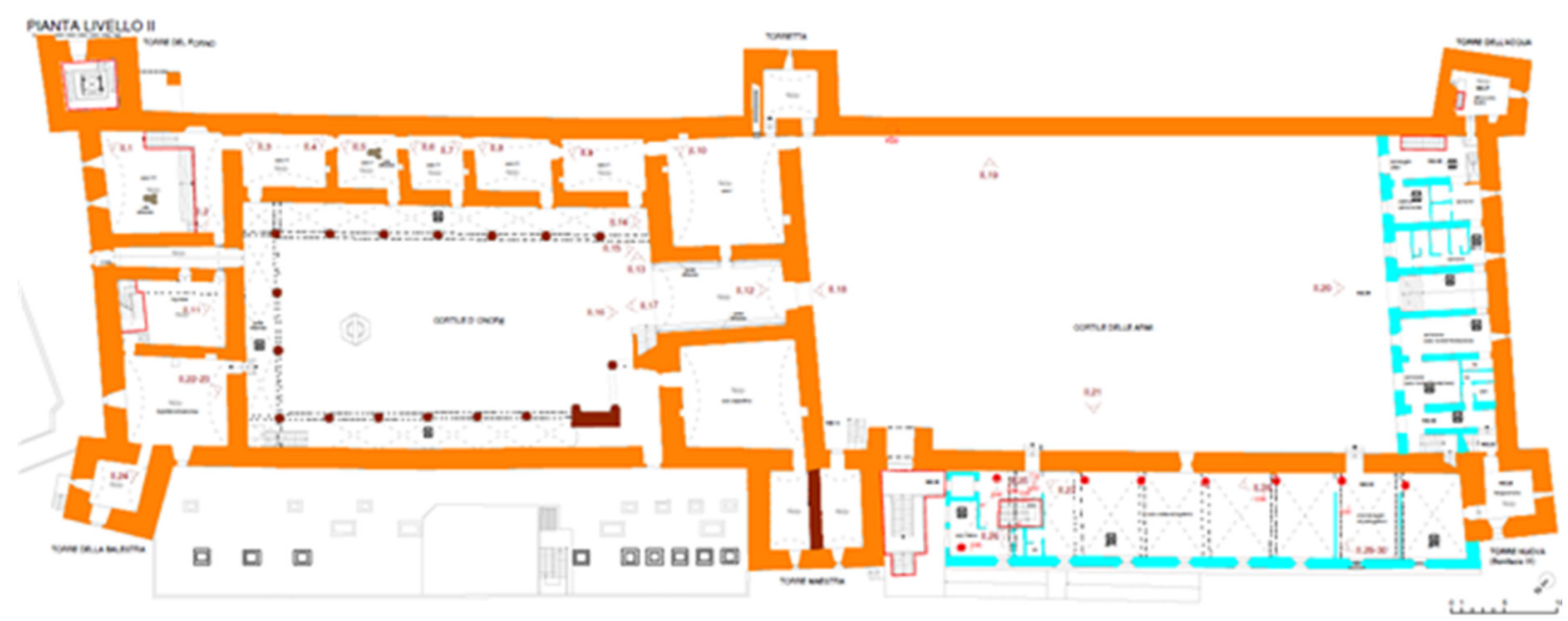

Figure 2: Detection of the masonry texture types: a) uncut stone masonry (US type, orange); b) dressed stone masonry (RS type, cyan).

After a direct visual inspections of both material textures (carried out by local dismantling or limited coring or video-endoscopic investigations), the MQI method was then used to recognize the ability of each masonry typology to behave monolithically. More specifically, the use of this method was aimed to evaluate the presence of certain parameters that define the "rule of the art", namely a set of construction devices that, if executed during the construction of a wall, provide a good behavior, ensuring its compactness. Among the meaningful parameters to examine in order to classify the two masonry texture types as being of "good quality", the following design features were considered: mortar mechanical properties (MM), wall leaf connections (cross interlocking, WC), horizontality of bed joints (HJ), resistant elements shape (SS), resistant elements dimensions (SD), staggering of vertical joints (VJ), conservation state and the mechanical properties of resistant elements (SM).

Three evaluations on compliance - Fulfilled (F), Partially Fulfilled (PF), and Not Fulfilled (NF) - with each parameter of the "rule of the art" were then considered in relation to three potential loading conditions: vertical (mainly static), in-plane and out-of-plane (mainly seismic, wind-generated, foundation subsidence, etc.). The approach was, in fact, to attribute a different 
score (ranging from 0 to 3, Table 2) to the above parameters based on the evidence that they affect the masonry quality with different degree depending on the loading condition, as confirmed by experimental evaluations [8][9] and case histories [10][11] and as reported in ancient and modern handbooks [12][13].

\begin{tabular}{lcccccccccc}
\hline & \multicolumn{3}{c}{$\begin{array}{c}\text { Vertical } \\
\text { loading }\end{array}$} & \multicolumn{3}{c}{$\begin{array}{c}\text { In-plane } \\
\text { loading }\end{array}$} & \multicolumn{3}{c}{$\begin{array}{c}\text { Out-of-plane } \\
\text { loading }\end{array}$} \\
\cline { 2 - 12 } & NF & PF & F & NF & PF & F & NF & PF & F \\
\hline Mortar mechanical properties (MM) & 0 & 1 & 2 & 0 & 0.5 & 1 & 0 & 1 & 2 \\
Wall leaf connections (WC) & 0 & 1 & 1 & 0 & 1 & 2 & 0 & 1.5 & 3 \\
Horizontality of bed joints (HJ) & 0 & 1.5 & 3 & 0 & 1 & 2 & 0 & 1 & 2 \\
Resistant elements shape (SS) & 0 & 0.5 & 1 & 0 & 1 & 2 & 0 & 0.5 & 1 \\
Resistant elements dimensions (SD) & 0 & 0.5 & 1 & 0 & 0.5 & 1 & 0 & 0.5 & 1 \\
Staggering of vertical joints (VJ) & 0 & 0.5 & 2 & 0 & 1 & 2 & 0 & 0.5 & 1 \\
Conservation state and the mechanical & 0.3 & 0.7 & 1 & 0.3 & 0.7 & 1 & 0.5 & 0.7 & 1 \\
properties of resistant elements (SM) & & & & & & & & & &
\end{tabular}

Table 2: Scores assigned on the parameters of the "rule of the art".

The scores obtained from Table 2 were then summed to obtain an overall score, the Masonry Quality Index (MQI), determined for each type of action.

$$
M Q I=S M \times(M M+W C+H J+S S+S D+V J)
$$

Starting from the concept of masonry efficiency connected to the fulfillment of all parameters of the "rule of the art" of Table 2, the value of MQI (between 0 and 10) was then used to define three different classes of decreasing vulnerability (denoted as Class $\mathrm{C}$ to Class A, Table 3 ), characterized not only by a different aptitude to the damaging (higher scores corresponds to a better seismic performance), but also by the variation of the damaging pattern (local or global damage mechanisms in the case of Class $\mathrm{A}$ and $\mathrm{B}$, diffused crumbling mechanisms for Class C). Furthermore, an estimate of the mechanical parameters of the two masonry types was obtained by means of the correlation given in [5] between the value of MQI and the values of the mechanical parameters (compressive strength, shear strength and modulus of elasticity) provided by Italian code [14].

\begin{tabular}{lccc}
\hline & \multicolumn{3}{c}{ Vulnerability classes } \\
\cline { 2 - 4 } & (inadequate behavior) & (average quality behavior) & (good behavior) \\
\hline Vertical loading & $0 \leq \mathrm{MQI}<2.5$ & $2.5 \leq \mathrm{MQI}<5.0$ & $5.0 \leq \mathrm{MQI} \leq 10$ \\
In-plane loading & $0 \leq \mathrm{MQI} \leq 3.0$ & $3.0<\mathrm{MQI} \leq 5.0$ & $5.0<\mathrm{MQI} \leq 10$ \\
Out-of-plane loading & $0 \leq \mathrm{MQI} \leq 4.0$ & $4.0<\mathrm{MQI}<7.0$ & $7.0 \leq \mathrm{MQI} \leq 10$ \\
\hline
\end{tabular}


Regarding the results obtained by the MQI method for both US and RS type masonry (Table 4), the following observations can be made:

- the low values of WC (no connection between the wall leaves) and VJ (vertical joints improperly staggered) indexes, leaded to classify the US masonry type in C-class for horizontal loading (in-plane and out-of-plane actions) and in B-class for vertical loading, indicating the poor quality and, consequently, the high seismic vulnerability of this masonry type. This can allow the attainment of a diffused crumbling able to lead to the collapse without the activation of the typical damage mechanisms (local or global failure modes);

- the RS type masonry, characterized by a well-organized bonding pattern, was classified in B-class for both in-plane and out-of-plane actions and in A-class for vertical loading, demonstrating a low level of seismic vulnerability (i.e. increased earthquake-resistance) and thus enhancing the monolithic behavior needed by the masonry to undergo the action of the typical local or global damage mechanisms.

\begin{tabular}{ccc}
\hline Masonry type & $\begin{array}{c}\text { Uncut stone } \\
\text { masonry } \\
\text { (US Type) }\end{array}$ & $\begin{array}{c}\text { Dressed rectangular stone } \\
\text { masonry } \\
\text { (RS Type) }\end{array}$ \\
\hline Vertical loading: & 3.5 & 5.0 \\
MQI value (masonry category) & $(\mathrm{B})$ & 4.5 \\
In-plane loading: & 3.0 & $(\mathrm{~B})$ \\
MQI value (masonry category) & $(\mathrm{C})$ & 5.0 \\
Out-of-plane loading: & 3.0 & $(\mathrm{~B})$ \\
MQI value (masonry category) & $(\mathrm{C})$ & $2.86-4.56$ \\
Compressive strength (N/mm $\left.{ }^{2}\right)$ & $2.05-3.39$ & $0.050-0.074$ \\
Shear strength (N/mm $\left.{ }^{2}\right)$ & $0.035-0.055$ & $1307-1859$ \\
Young modulus (N/mm $\left.{ }^{2}\right)$ & $1007-1455$ & $523-744$ \\
Shear Modulus $\left(\mathrm{N} / \mathrm{mm}^{2}\right)$ & $403-582$ & \\
\hline
\end{tabular}

Table 4: Masonry Quality Index (MQI) method: results of masonry analysis.

\subsection{Rigid Macro-Block (RMB) method}

At this evaluation level, it was necessary to identify the possibility of suffering local mechanisms (mainly out-of-plane ones) that involve only defined portions of the entire structure, which, being not able to redistribute their seismic forces to the rest of the building [17][18], cannot be accurately analyzed through a pushover analysis (Equivalent Frame method, EF).

According to this, a macro-element approach based on the limit analysis theorems (Rigid Macro-Block method, RMB) was used complementarily to the EF approach. The structure was thus idealized as an assemblage of elementary substructures, modelled as a system of rigid bodies, whose geometry and distribution were defined either by analyzing their structural characteristics (e.g. quality of the existing connections, constructive phases, structural discontinuities, etc.) or according to the observed damage pattern produced by past earthquakes in similar 
structures (damages consequent to past seismic events allow to predict the occurrence of recurrent modes and collapse mechanisms, [15][16]). In such a context, a number of potential collapse scenarios (mostly out-of-plane failure modes, Figure 3 and Figure 4) were selected and the corresponding values of the seismic activation multiplier $(\lambda)$ were evaluated according to the methodology (Theorem of Virtual Works) proposed by the Italian code [14].

These values were then used to assess the acceleration (seismic spectral acceleration, $\mathrm{a}_{0}{ }^{*}$ ), which leads to the onset of each mechanism, through the following expression:

$$
a_{0}^{*}=\frac{\lambda g}{e^{*} C F}
$$

where $g$ is the gravity acceleration, $e^{*}$ represents the ratio of participating mass and $C F$ denotes the confidence factor.
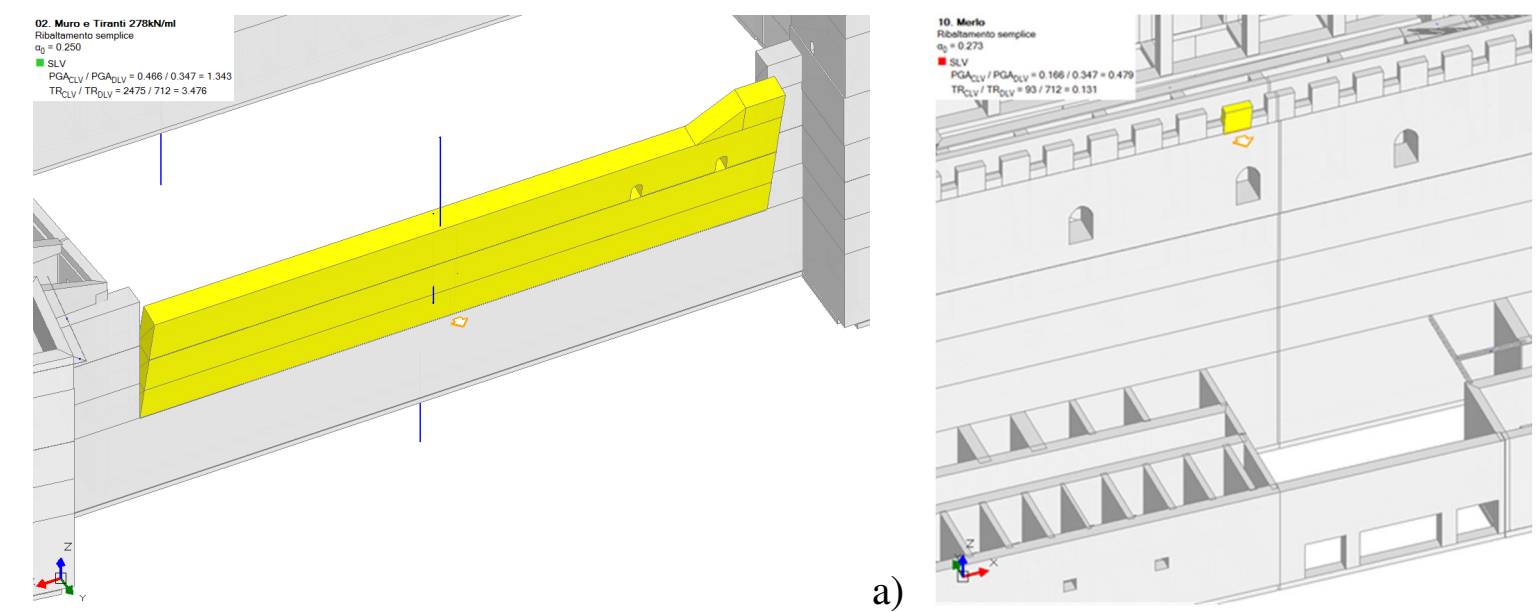

Figure 3: Mechanisms of simple overturning: a) south-west wall (Mec-01); b) unlinked masonry portions (merlons, Mec-02).

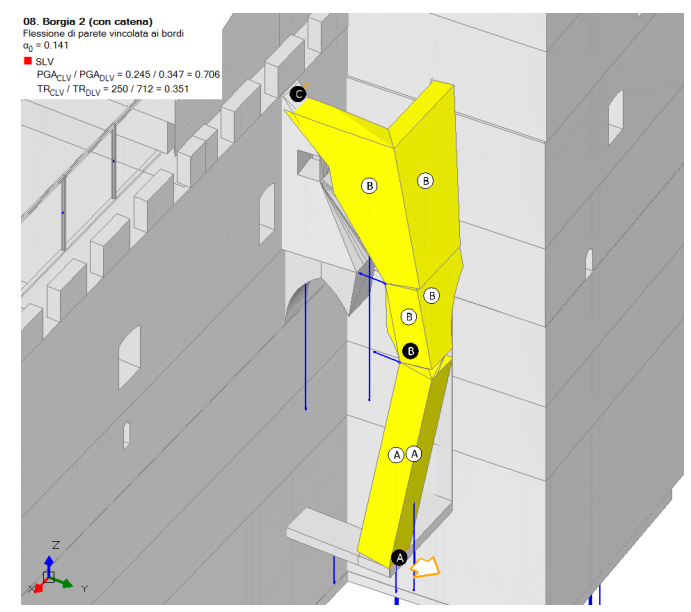

Figure 4: Mechanisms of vertical bending (vertical arch mechanisms): north-east tower (Lucretia Borgia room, Mec-03).

Finally, the seismic evaluation was based on the Seismic Safety Index $\left(I_{s s}\right)$, obtained as the ratio between the maximum value of the acceleration (seismic capacity, $I M_{c a p}=a_{0}{ }^{*} q$, where $a_{0}{ }^{*}$ is given by (2) and $q$ represents the behavior factor, which was assumed equal to 2.0 according to [19]) compatible with the fulfillment of the assumed performance level (Life Safety) and the reference target value of the seismic demand $\left(I M_{d e m}\right)$ given by: 


$$
I M_{\text {dem }}=\left\{\begin{array}{l}
a_{g} S \quad \text { for mechanisms at ground level } \\
\max \left(a_{g} S ; S_{e}\left(T_{1}\right) \psi(Z) \gamma\right) \quad \text { for mechanisms at a certain heights }
\end{array}\right.
$$

being: $a_{g}$ (assumed equal to $0.251 \mathrm{~g}$ ) the seismic spectral acceleration on rock (at $T=0$ ), $S$ (assumed equal to 1.160) a factor depending on the ground type (deposits of very dense sand and stiff clay), $S_{e}\left(T_{1}\right)$ the spectral acceleration for the elastic design (at $\left.T=T_{1}\right), \psi(Z)$ a normalized function describing the amplitude of the first vibration mode of the structure (approximated as $\psi(Z)=Z / H$, where $Z$ is the height, with respect to the foundation level, of the centroid of all inertial masses involved in the mechanism and $H$ is the height of the structure); $\gamma$ a modal participation factor.

\begin{tabular}{ccccc}
\hline & $\begin{array}{c}\text { Activation multiplier } \\
{[\lambda]}\end{array}$ & $\begin{array}{c}\text { Seismic capacity } \\
{\left[I M_{\text {cap }}\right]}\end{array}$ & $\begin{array}{c}\text { Seismic demand } \\
{\left[I M_{\text {dem }}\right]}\end{array}$ & $\begin{array}{c}\text { Seismic Safety Index } \\
{\left[\mathrm{I}_{\text {ss }}\right]}\end{array}$ \\
\hline Mec-01 & 0.086 & $0.160 \mathrm{~g}$ & $0.347 \mathrm{~g}$ & 0.460 \\
Mec-02 & 0.273 & $0.166 \mathrm{~g}$ & $0.347 \mathrm{~g}$ & 0.478 \\
Mec-03 & 0.141 & $0.245 \mathrm{~g}$ & $0.347 \mathrm{~g}$ & 0.706 \\
\hline
\end{tabular}

Table 5: Rigid Macro-block (RMB) method: results of analyses.

Results from the RMB method, obtained by using the commercial software Aedes Pcm [20], are summarized in Table 5. As suggested by [21], it is worth pointing out how, in spite of $I_{s S}$ values less than one should indicate the mechanisms are not verified, lower values of the minimum level of safety (0.780) are acceptable if it is demonstrated that interventions needed to fully satisfy structural checks are in conflict with preservation requirements. Within this approach, by analyzing the $I_{s s}$ values it was possible to observe how the mechanisms of simple overturning (Mec-01 and Mec-02) highlighted a critical situation, with values of the safety index considerably lower than the minimum level of safety proposed by code requirements. Even the mechanism Mec-03 (mechanism of vertical bending) showed a critical scenario, but a value of the $I_{s s}$ index significantly higher (0.706).

\subsection{Equivalent Frame (EF) method}

According to the RMB approach, the assessment of the structure was developed by idealizing the entire structure as an assemblage of elementary structural elements that being not able to redistribute their seismic forces to the rest of the building, suffered local mechanisms (mainly out-of-plane ones) that involve only a portion of the total seismic structural mass. Hence, at this level of investigation, it was necessary to simulate the global seismic response (in-plane behavior) of the entire structure.

To this end, it is noteworthy to point out that, despite its apparent regularity, the Rocca Albornoziana fortress is actually a stratified structure, which consists of an articulated arrangement of structural units, subjected to various transformations occurred over the centuries (demolitions, enlargements, etc.). Within this context, the possibility to analyze separately these structural units, rather than considering the numerical analysis of the entire structure, derives from the observation that the seismic response of the building can be properly evaluated analyzing the individual contribution of the portions having more homogeneous structural characteristic, on the basis of the structural morphology (discontinuities, lack of constraints, different height of the portions, different height of the floors, etc.) and the unitariness of the interventions. 
Adopting this practical strategy (as suggested in [19][22]), the entire complex was thus split up into three main structural units (see units SU-01, SU-02 and SU-03 of Figure 5), characterized by relative chronological relationship.

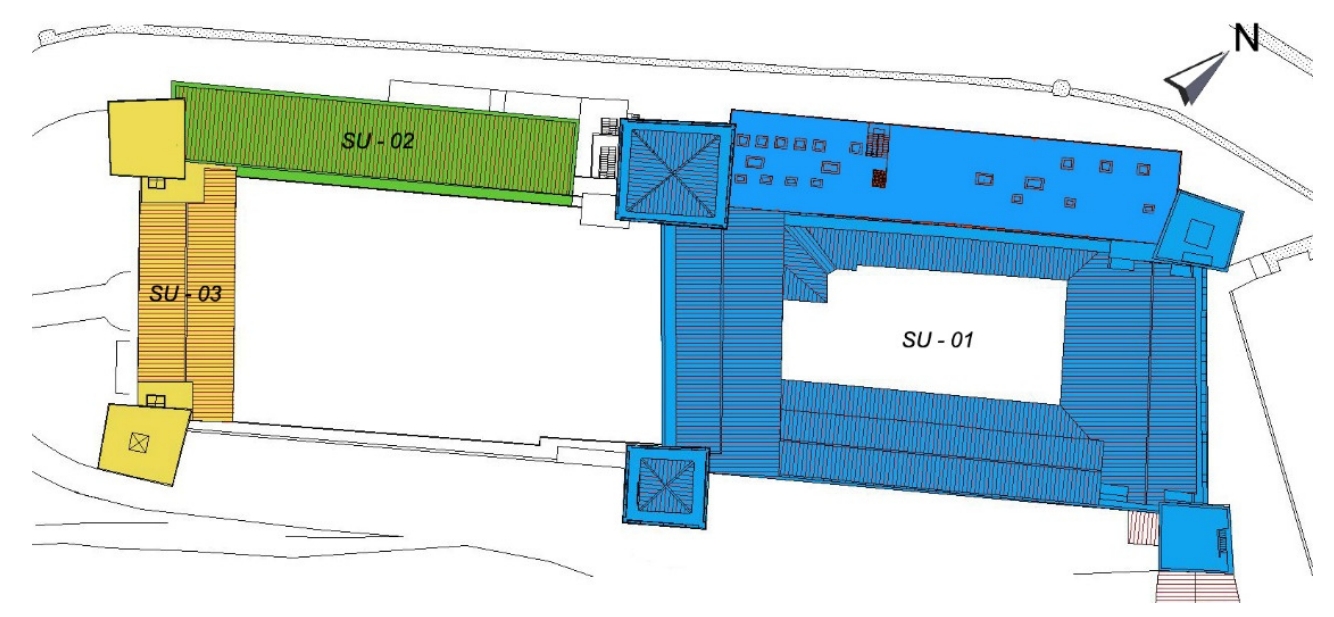

Figure 5: Fortress structural units.

At this scale level, the material and constructive knowledge of the building was, even more than in the previous levels, a fundamental prerequisite to perform a reliable evaluation of the seismic vulnerability of the structure in its present state. Unfortunately, since to reduce the impact on conservation, exhaustive mechanical characterization tests could not be used, the lower knowledge level (LC1) available in the Italian Code for existing structures was assumed. Therefore, data on the material properties were estimated through the Masonry Quality Index (MQI) method, by assuming, for each material, the mean values for elastic moduli and the lower bounds values of strength (further divided by the confidence factor $C F=1.12$ according to [21]) listed in Table 4. Table 6 summarizes the values used for the analysis.

\begin{tabular}{ccc}
\hline & $\begin{array}{c}\text { Uncut stone } \\
\text { masonry } \\
\text { (US Type) }\end{array}$ & $\begin{array}{c}\text { Dressed rectangular stone } \\
\text { masonry } \\
\text { (RS Type) }\end{array}$ \\
\hline Compressive strength $\left(\mathrm{N} / \mathrm{mm}^{2}\right)$ & 2.05 & 2.86 \\
Shear strength $\left(\mathrm{N} / \mathrm{mm}^{2}\right)$ & 0.035 & 0.050 \\
Young modulus $\left(\mathrm{N} / \mathrm{mm}^{2}\right)$ & 1231 & 1583 \\
Shear Modulus $\left(\mathrm{N} / \mathrm{mm}^{2}\right)$ & 492 & 633 \\
\hline
\end{tabular}

Table 6: Values of the mechanical parameters used for the pushover analysis.

Under such conditions, non-linear static analyses, aimed at evaluating the accelerations leading each structural units to a given performance level (Life Safety), were carried out to investigate the global seismic response of the fortress [23][24][25][26]. More specifically, each units was modelled by an equivalent framed system composed of beam elements (describing both the wall piers and spandrel walls) loaded with a distribution of in-plane forces, which were monotonically increased to simulate the effects of the seismic loads (Equivalent Frame method, EF). As suggested by the Italian Code [19], two systems of horizontal forces, both depending on the mass distribution, were applied (not simultaneously) along the two principal directions 
(perpendicular to one another) of the structure: the first load distribution was directly proportional to the displacement of the corresponding first modal shape of the structure (modal distribution), while for the second it was assumed a linear variation of forces along the height (massproportional distribution).

In order to identify the most demanding condition, it was decided to perform an analysis for each distribution, varying the loading patterns (modal and mass-proportional distribution), the directions (East-West and North-South) and sign of excitation (resulting in a total of 8 nonlinear static analysis). Each analysis, carried out in displacement control, proceeded to the calculation of the load distribution that produces the maximum seismic force that is bearable by the structure, i.e. the level of the Peak Ground Acceleration (PGA) needed for inducing the first failure mechanism. The results (provided by PCM program [20], Figure 6) were presented in the form of pushover curves where the displacement of a selected control point (measured at the top of each structural unit) was plotted as a function of the total base shear.

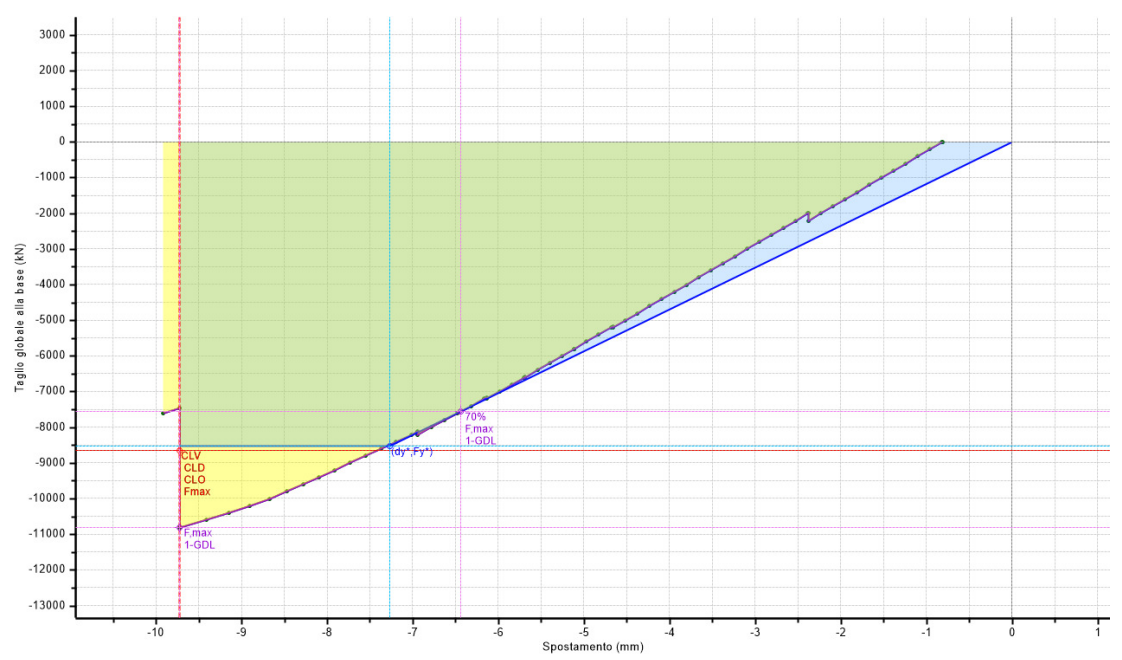

Figure 6: Equivalent Frame (EF) method: unit SU-02 structural response in West direction (the equivalent capacity curve (purple line) and the equivalent bilinear diagram (blue line)).

As in the previous analyses (RMB method), the seismic vulnerability was synthetically evaluated in terms of seismic vulnerability index $\left(I_{s s}\right)$. In all structural units, $I_{s s}$ values confirmed the results obtained with the RMB method as the seismic capacity of each system was always lower than the minimum level of safety proposed by code requirements, highlighting the inability of the fortress to fulfill the required performance levels prescribed by the Italian code.

\begin{tabular}{ccccc}
\hline $\begin{array}{c}\text { Structural } \\
\text { unit }\end{array}$ & Loading condition & $\begin{array}{c}\text { Seismic } \\
\text { capacity } \\
{\left[I M_{\text {cap }}\right]}\end{array}$ & $\begin{array}{c}\text { Seismic } \\
\text { demand } \\
{\left[I M_{\text {dem }}\right]}\end{array}$ & $\begin{array}{c}\text { Seismic } \\
\text { safety index } \\
{\left[\mathrm{I}_{\mathrm{ss}}\right]}\end{array}$ \\
\hline SU-01 & $\begin{array}{c}\text { South directed force } \\
\text { (modal distribution) }\end{array}$ & $0.147 \mathrm{~g}$ & $0.347 \mathrm{~g}$ & 0.424 \\
SU-02 & $\begin{array}{c}\text { West directed force } \\
\text { (mass-proportional distribution) }\end{array}$ & $0.090 \mathrm{~g}$ & $0.347 \mathrm{~g}$ & 0.251 \\
SU-03 & $\begin{array}{c}\text { North directed force } \\
\text { (modal distribution) }\end{array}$ & $0.184 \mathrm{~g}$ & $0.347 \mathrm{~g}$ & 0.530 \\
\hline
\end{tabular}

Table 7: Equivalent Frame (EF) method: results of analyses. 
As pointed out in Table 7, the structural unit that result to be more vulnerable was unit SU02 in case of seismic loading acting in the West direction (for mass-proportional distribution). In this direction, the structure exhibited a poor performance (the analysis stopped at level of the horizontal loads corresponding to about the $25 \%$ of the overall weight of the unit), as a result of the progression of the in-plane bending failure of the arcade arches in longitudinal direction (South-North axis, Figure 7).

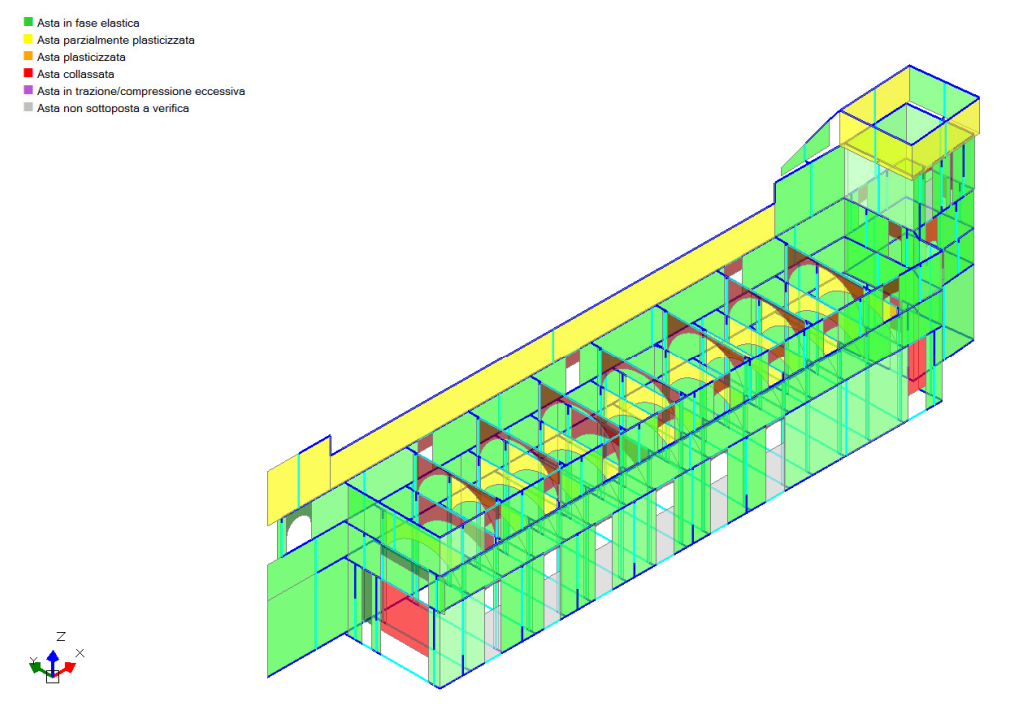

Figure 7: Equivalent Frame (EF) method: cracking pattern in the unit SU-02.

\section{CONCLUSIONS}

The central objective of the present paper was to propose and test, through the application of a step-by-step analysis procedure on a reference case (the Rocca Albornoziana fortress), a general methodology of seismic analysis articulated on three modelling strategies of different complexity: Masonry Quality Index (MQI) method, Rigid Macro-Block (RMB) method and Equivalent Frame (EF) method.

To this end, a quick evaluation procedure (MQI method) was used, on the one hand, to express a synthetic judgment about the seismic vulnerability of the different masonry texture types and, on the other one, to provide a numerical estimate of their mechanical properties. Conversely, the application of the RMB method on a wide set of potential collapse scenarios permitted to highlight some structural deficiencies in the out-of-plane behavior of the structure, mainly associated with the presence of overturning mechanisms. Finally, the last level of analysis, the EF method, was approached by analyzing the individual contribution of the different structural units forming the fortress. In all examined cases, the numerical analyses provided valuable pictures of all possible critical conditions, thus giving useful hints for reconstruction. More specifically, the results highlighted some structural deficiencies also in the in-plane behavior, showing how the detected damage was mainly associated with the presence of in-plane bending failure mechanisms.

Accepting the uncertainties and constraints common for historic masonry constructions, one of the main outcomes of this research may therefore be in the awareness that comparing different approaches for the analysis of these structures is fundamental to cover the unavoidable unknowns that always affect the construction and the analysis approaches. Furthermore, only a clear understanding of the structural behavior based on a comparative methodology may assure the definition of reliable strengthening interventions, thus reducing the extent of the remedial measures. 


\section{ACKNOWLEDGEMENTS}

The financial support of the General Directorate for the Landscape, Fine Arts, Architecture, and Contemporary Art (DG PaBAAC) - Ministry of Cultural Heritage and Activities and Tourism (MiBACT) is gratefully acknowledge. The contributions of Prof. M. Cecconi and Eng. A. Vecchietti is greatly acknowledge. The authors are also grateful to Arch. B. Gori and Eng. A. Giannantoni for their suggestions and support.

\section{REFERENCES}

[1] L. Binda, A. Saisi, Research on historic structures in seismic areas in Italy. Progress in Structural Engineering and Materials, 7, 71-85, 2005.

[2] D.F. D'Ayala, S. Paganoni, Assessment and analysis of damage in L'Aquila historic city centre after $6^{\text {th }}$ April 2009. Bulletin of Earthquake Engineering, 9, 81-104, 2011.

[3] F. Karantoni, G. Bouckovalas, Description and analysis of building damage due to Pyrgos, Greece earthquake. Soil Dynamic Earthquake Engineering, 16, 141-50, 1997.

[4] M. Tomazevic, I. Klemenc, M. Lutman, Seismic behavior of masonry buildings. Lesson from the Bovec earthquake of April 12, 1998. VIII Canadian conference of earthquake engineering, Vancouver, Canada, June 13-19, 1999.

[5] A. Borri, M. Corradi, G. Castori, A. De Maria, A method for the analysis and classification of historic masonry. Bulletin of Earthquake Engineering, 13, 1-19, 2015.

[6] Umbria regional law n. 18 (23.10.2002), Norme in materia di prevenzione sismica del patrimonio edilizio. B.U.R. n. 48 (06.11.2002) (in Italian).

[7] G. Manfredi, M. Dolce, The state of Earthquake Engineering Research in Italy: the ReLUIS-DPC 2005-2008 Project, 1-50. Doppiavoce, 2009.

[8] M. Corradi, A.I. Osofero, K. Coventry, A.E. Richardson, C. Udeaja, T. Vo, Analysis and classification of historic construction within the north-east of England. $16^{\text {th }}$ International Conference on Structural Faults and Repair (SFR2014), London, UK, July 8-10, 2014.

[9] L. Rovero, V. Alecci, J. Mechelli, U. Tonietti, M. De Stefano, Masonry walls with irregular texture of L'Aquila (Italy) seismic area: validation of a method for the evaluation of masonry quality. Materials and Structures, 49, 2297-2314, 2016.

[10] L. Righetti, M. Corradi, M. Lim, L. Amess, J. Charlton, Structural analysis of the $15^{\text {th }}$ century bell tower, St Nicholas Cathedral, Newcastle Upon Tyne. $13^{\text {th }}$ Canadian masonry symposium (CMS), Halifax, Canada, June 4-7, 2017.

[11] L. Rovero, S. Fratini, The Medina of Chefchaouen (Morocco): A survey on morphological and mechanical features of the masonries. Construction and Building Materials, 47, 465-479, 2013.

[12] S. Mastrodicasa, Dissesti statici delle strutture edilizie: diagnosi, consolidamento, istituzioni teoriche. Hoepli, 1978 (in Italian).

[13] A. Giuffrè, Letture sulla meccanica delle murature storiche. Kappa, 1999 (in Italian).

[14] IMIT Circ. n. 617 (02.02.2009), Istruzioni per l'applicazione delle Nuove Norme Tecniche per le Costruzioni di cui al decreto ministeriale 14 gennaio 2008. Italian Ministry of Infrastructures and Transportation. G.U. n. 47 (26.02.2011) (in Italian). 
[15] D. D'Ayala, E. Speranza. Definition of collapse mechanisms and seismic vulnerability of historic masonry buildings. Earthquake Spectra, 19, 479-509, 2003.

[16] S. Cattari, S. Degli Abbati, D. Ferretti, S. Lagomarsino, D. Ottonelli, A. Tralli. Damage assessment of fortresses after the 2012 Emilia earthquake (Italy). Bulletin of Earthquake Engineering, 12, 2333-2365, 2014.

[17] R. Cardoso, M. Lopes, R. Bento. Seismic evaluation of old masonry buildings. Part I: Method description and application to a case-study. Engineering Structures, 27, 20242035, 2005.

[18] L. Binda, A. Saisi. Research on historic structures in seismic areas in Italy. Progress in Structural Engineering and Materials, 7, 71-85, 2005.

[19] NTC 2008 (14.01.2008), Nuove Norme Tecniche per le Costruzioni. Directive of the Prime Minister. G.U. n. 29 (04.02.2008) (in Italian).

[20] Aedes Software (2014), PCM: Progettazione di costruzioni in muratura. $<\mathrm{http}: / / \mathrm{www}$.aedes.it>.

[21] DPCM 2011 (09.02.2011), Assessment and mitigation of seismic risk of cultural heritage with reference to the Italian Building Code (NTC 2008). G.U. n. 47 (26.02.2011) (in Italian).

[22] EN 1998-1, Eurocode 8. Design provisions for earthquake resistance of structures. Part 1-1: General rules - seismic actions and general requirements for structures. Comité Européen de Normalisation, Brussels, Belgium; 2004.

[23] P. Roca, C. Molins, A.R. Marí. Strength capacity of masonry wall structures by the Equivalent Frame Method. Journal of Structural Engineering, 131, 1601-1610, 2005.

[24] F. Parisi, N. Augenti. Uncertainty in seismic capacity of masonry buildings. Buildings, 2, 212-230, 2012.

[25] S. Lagomarsino, A. Penna, A. Galasco, S. Cattari. TREMURI program: an equivalent frame model for the nonlinear seismic analysis of masonry buildings. Engineering Structures, 56, 1787-1799, 2013.

[26] M. Acito, C. Chesi, G. Milani, S. Torri. Collapse analysis of the Clock and Fortified towers of Finale Emilia, Italy, after the 2012 Emilia Romagna seismic sequence: Lesson learned and reconstruction hypotheses. Construction and Building Materials, 115, 193$213,2016$. 